\section{Picture-book of economic botany}

The Power of Plants. By Brendan Lehane. Pp. 288. (John Murray: London, 1977.) $£ 12.50$.

A 'POWER OF' something or other, usually good, is a common Irish expression and this profusely illustrated book by an Irish author does indeed suggest a botanical Irish stew, thick, nourishing and well flavoured, but with far more varied vegetable ingredients. The manifold relationships of plants to man in feeding, healing, killing, pleasing, interesting and fooling him provide the main theme. As the author says at the beginning "Plants are the foundation of all existence of humans and animals, of society and civilization, of our dreams. They are the source of our nourishment and health, pleasures and ecstasies; they sustain religions, cultures, civilizations. In the end they can kill us, and return us to the soil on which they themselves feed".

The intent is to portray all this dependence graphically, in a vividly written easily understood text summarising a vast amount of information picked from a wide range of publications and in a wealth of coloured and black-and-white illustrations from an even wider range of sources. Such a medley raises the question of for whom the book is primarily intended. Although no professional botanist can fail to find something entertaining in the text or illustrations with which he has previously been unacquainted, it would seem fair to regard the book as an elementary introduction to economic botany and ethnobotany.

Covering so much, it necessarily does not go deeply into anything but succeeds in maintaining interest by surprising juxtapositions of statements and illustrations. Moreover, each of the five sections being chopped into numerous small more or less self-contained subsections, it makes little demand on the reader's mental digestion. It can be recommended to school teachers of biology as a source of unusual titbits and to the general public as a revelation of the extraordinarily diversified and very important impact of the plant world on human life.

The first section, entitled "Power to Survive", deals with plants as part of the cycle of nature and with their successful adaptation to very different environmental conditions. The second, "Power to Sustain", covers the origins of agriculture and the major economic crops of the world, such as the breadmaking cereals, rice, maize, potato and olive, together with vegetables, fruits and culinary herbs; one illustration even shows 18 kinds of bread from the late Stone Age and Ancient Egyptian and Classical times onwards.

The third section, "Power to Heal and Kill", is concerned with medicinal and poisonous plants - the two are of ten the same, their effect for good or ill then depending on dosage-and a discussion of their lethal use provides the opportunity to portray such characters as Lucrezia Borgia, Catherine de Medici, Madame la Voisin, Crippen and Graham Young, as well as harmless and beneficient herbalists such as Dioscorides, Paracelsus, Bock, Mattioli, Fuchs, and their like. There is an excellent little chapter here on the "Art of the Herbals".

The fourth section, "Power to Alter Consciousness", has subsections on a diversity of hallucinogens and beverages, including peyote, tobacco, kavakava, coffee, magic mushrooms, cola, tea, wine, beer, cannabis, morning glory, together with their erotic and magical associations. The fifth and last section, "Power on the Spirit", deals with plants in religion, art and horticulture.

The main attraction of this book obviously is in its 800 or more illustrations. These adorn every page and completely cover nearly half of them. Probably never before has such a diversity of illustrations relating to plants and to men associated with them been gathered into one book. They include reproductions from early manuscripts and printed herbals and from drawings and paintings of all kinds, as well as diagrams, modern aerial photographs and electron micrographs. To seek out such array must have cost an enormous amount of erudite enquiry

\section{Aspects of lichen ecology}

Lichen Ecology. Edited by M. R. D. Seaward. Pp. 550. (Academic: London and New York, 1977.) £23; \$44.90.

THE edited volume has the particular advantage of being able to capitalise on available expertise in specific fields, but perhaps sometimes the disadvantage of being not well coordinated. If the latter applies it is either an editorial fault, or it reflects the embryonic or unbalanced state of research interest in the subject. The present volume falls into the latter category.

Most of the eleven chapters would seem to fall into three distinctive groups. Firstly, chapters 4 and 5 and parts of chapter 6 focus attention on the interactions of lichens with animals, a subject which has received increased attention recently-in particular, the association of distinctive invertebrate for many come from sometimes obscure sources. It is thus most regrettable and exasperating that these sources are rarely indicated with precision, sometimes not at all, or else inconsistently. Thus the illustration of Aristolochia clematitis on the title page has no caption at all; that of Artemisia vulgaris on p17 is said to be from "the seventh century Viennese edition of Dioscorides"; that of Silene linifolia (not linoides) on p161 from "the Codex Aniciae Julianae"; those of Dipsacus, Urtica and Chenopodium on pp164 and 165 from "the Viennese manuscript known as the Wiener Dioskurides". Thus one might assume that they come from at least four different works. In fact they are all reproduced from the excellent Graz facsimile of the celebrated sixth-century Byzantine herbal officially known as the Codex Aniciae Iulianae Picturis illustratus nunc Vindobonensis Med. Gr. I, but often called Codex Vindobonensis of Dioscorides, brought to Vienna from Constantinople in the sixteenth century by the ambassador Busbecq and now in the Nationalbibliothek, Vienna. The illustration on p150 described as "A seventeenth-century woodcut" is a copy by $P$. Lambeck (Lambecius) of a coloured drawing in the same codex.

Nobody, however, should be put off from enjoying this attractive and unusual book by the few minor imperfections.

William T. Stearn

William T. Stearn, formerly a Senior Principal Scientific Officer in the Department of Botany, British Museum (Natural History), is a Visiting Professor in the Department of Botany and Agricultural Botany, University of Reading, UK.

populations with lichens. Further interest may be stimulated despite the difficulties of invertebrate identification being superimposed on those of lichens, an obvious case for cooperation between specialists. Chapters 3, 6 and 10 all touch on lichen-lichen interactions in relation to competition and successional phenomena (also neglected fields of study), and together these contributions provide a useful coverage of our present understanding of these 'ecosystem' topics.

As the editor states on p3 it is perhaps premature to attempt a worldwide review of lichens from the phytogeographical point of view. Nevertheless, having chosen to include accounts of three major biotic zones (chapters 6, 7 and 8), it is a pity that nothing is said of tropical and subtropical regions and that consideration of temperate regions is restricted to the British Isles. Admittedly these regions are floristically much richer and more 